\title{
Welfare Gains from Quality Certification OF INFANT FoOdS: RESUlTS FROM A MARKET EXPERIMENT IN MALI
}

\author{
William A. Masters and Diakalia Sanogo
}

\begin{abstract}
In low-income countries, malnutrition is often most severe among infants of six to twenty-four months. They need higher-density foods than the family diet, but density is a credence attribute. We hypothesize that the premium now paid for heavily advertised brands reflects demand for quality assurance, which could be provided at lower cost to competing firms through third-party certification. We use a new market experiment to find that mothers' average willingness-to-pay for certification is about $\$ 1.75 / \mathrm{kg}$, or four times its cost, so that total economic-surplus gains from introducing certification to Mali would be on the order of $\$ 1$ million annually.
\end{abstract}

Key words: asymmetric information, child nutrition, complementary foods.

The nutrition of infants is a major public health and welfare challenge in developing countries, where an estimated one-third of preschool children have had their growth stunted by inadequate diets, and over half of all child deaths are associated with malnutrition (UN and IFPRI). ${ }^{1}$ Figure 1 shows the average size of children in Mali, relative to international norms: they become increasingly thin between four and twelve months of age, and increasingly stunted between four and twenty-four months. This pattern is typical of very low-income people around the world (e.g., Martorell and Habicht, p. 246-48; Lutter, p. 97). After about two years of age nutritional status often improves, at least in terms of weight-for-height, but the early experience of severe malnutrition can cause lifelong impairment (Martorell, 1995; 1999).

Many factors could cause slow growth during the four to twenty-four month period, such as exposure to disease, age-specific micronutrient needs, and behavioral factors in child

\footnotetext{
William A. Masters is a professor and Diakalia Sanogo is a postdoctoral research associate in the Department of Agricultural Economics at Purdue University.

The authors thank the Africa Bureau of USAID for funding under U.S. Department of Agriculture Collaborative Agreement 583148-6-015; Ousmane Sanogo and Bakary Coulibaly of the Institut d'Economie Rurale in Mali for research support; and numerous colleagues and two anonymous referees for valuable suggestions.

${ }^{1}$ We use the term "infant" as the airlines do, for children up to 24 months, because of its relevance for dietary patterns. The term is used differently in mortality statistics, where "infant" mortality refers to death in the first twelve months, and "child" mortality is deaths in the first five years.
}

care, but total food intake is often a binding constraint on growth among very low-income children (Smith and Haddad, 2000a, 2000b). Children's most severe nutritional shortfalls coincide with the period in which they need more nutrients than are available in breastmilk, but cannot yet digest sufficient quantities of family foods (Lutter). At this time children need foods of unusually high nutrient density (Brown, Dewey, and Allen), and interventions to increase their use have repeatedly been shown to improve nutritional status (Caulfield, Huffman, and Piwoz).

This article asks whether failure to provide enough high-density foods might be due to the difficulty of observing nutrient density, which could be remedied through product testing and quality assurance. We use a new kind of market experiment to elicit mothers' demand for information about their infant foods, and measure the potential welfare gains from introducing a quality certification program. If quality certification proves to be an effective remedy for market failure in the provision of infant foods, it could provide an unusually welltargeted mechanism to improve the welfare of very poor children.

\section{The Market for Complementary Foods and Quality Certification}

Appropriate complementary foods for infants can be prepared at home from raw ingredients, 


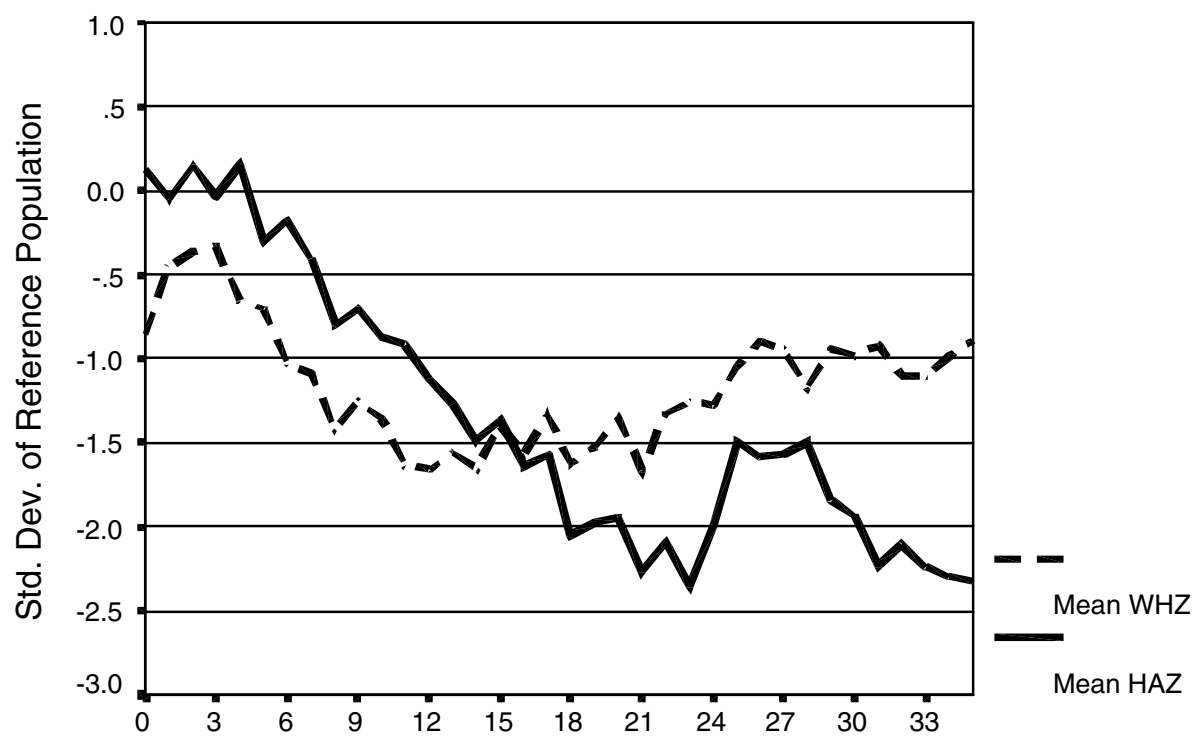

Age in Months

Source: Demographic and Health Survey, 1995/96

Note: Reproduced with thanks from Penders, Staatz, and Tefft, 2000.

\section{Figure 1. Weight-for-height (WHZ) and height-for-age (HAZ) in Mali, by age}

or purchased from industrial sources as a ready-to-cook or precooked product. Home production is very laborious, and there are significant scale economies from industrial production. The dominant industrial brand, in Mali as in many other countries, is Nestlé's precooked Cérélac. Cérélac is heavily advertised, expensively packaged, and sells for many times the cost of a nutritionally-equivalent generic product (Dijkhuizen). Other global and regional brands charge similarly high premia over ingredient costs, and are often sold through high-markup retailers such as pharmacies.

Price levels and brand names for infant foods in Mali are shown in table 1. The dominant brand (Cérélac) has two much-smaller competitors (Blédilac and Farinor) that charge similarly high prices, and there are also two donor-supported competitors (MISOLA and UCODAL) at much lower prices. Such lowcost infant foods have been introduced by public agencies in many developing countries, beginning with Incaparina in the early 1960s (Scrimshaw). As documented by Lutter and Huffman or Porter and Shafritz, these have generally been well accepted when procured by a donor agency for subsidized distribution, but they attract very little commercial demand despite their low price.
We hypothesize that an important factor influencing the market demand for infant foods is that a key attribute of these products, their nutrient density, is to a considerable degree not observable by the purchaser. In the terminology established by Darby and Karni, density is a "credence" attribute, a desired quality whose presence cannot be seen even after use, because there are too many confounding factors for its effect to be visible. ${ }^{2}$

For consumers to discover whether a given food has been adequately fortified, they would have to use it over a long enough period and a sufficiently large sample of children, to see a difference in child growth given the effects of disease episodes, parasite load, or genetic potential. Thus for any given consumer, nutrient density is effectively unobservable, and when making initial or repeat purchases

\footnotetext{
${ }^{2}$ Archetypical examples of goods with important credence attributes are pharmaceutical products and medical or educational services. Credence attributes can be contrasted with "search" attributes that are observable before use (and thus can guide initial purchase), and "experience" attributes whose effects are observable after use (and thus guide repeat purchases), using terms due to Nelson $(1970,1974)$. In the case of infant foods, search attributes are price, packaging, and brand identity, while experience attributes are palatability, digestibility, and contamination causing an immediate illness. Only nutrient density or contamination causing delayed reactions are credence attributes, with effects hidden by intervening factors.
} 
Table 1. Infant Foods for Sale in Bamako, Mali (1999)

\begin{tabular}{|c|c|c|c|c|}
\hline \multirow[b]{2}{*}{ Brand Name } & \multirow[b]{2}{*}{ Packaging } & \multicolumn{3}{|c|}{ Retail Prices (FCFA/unit) ${ }^{\mathrm{a}}$} \\
\hline & & Open Market & Stores & Pharmacy \\
\hline Cérélac (wheat) & 400-g can & 1400 & 1500 & 1615 \\
\hline Cérélac (wheat) & $200-\mathrm{g}$ box & 600 & & 850 \\
\hline Cérélac (rice) & 400 -g can & & 1600 & \\
\hline Cérélac (wheat/banana) & 400 -g can & & 1750 & \\
\hline Cérélac (wheat + three fruits) & 400-g can & & & 2240 \\
\hline Blédilac $^{\mathrm{b}}$ (wheat) & $250-\mathrm{g}$ can & & & 1270 \\
\hline Blédina $^{\mathrm{b}}$ (lactée fruits) & $250-\mathrm{g}$ box & & & 1830 \\
\hline Farinor $^{\mathrm{b}}$ (maize/soy) & $400-\mathrm{g}$ box & & 1690 & 1750 \\
\hline MISOLA & $500-\mathrm{g}$ bag & & & $300^{c}$ \\
\hline UCODAL (e.g. Sinba) & 200 -g bag & & $200^{c}$ & \\
\hline
\end{tabular}

Source: Trèche for all except MISOLA and UCODAL, for which data are from authors' interviews.

${ }^{\mathrm{a}}$ In 1999 , US $\$ 1.00=600$ FCFA.

${ }^{\mathrm{b}}$ Farinor is a regional brand imported to Mali from Côte d'Ivoire. Blédilac and Blédina are European labels.

${ }^{\mathrm{c}}$ In 1999, MISOLA and UCODAL were available only from the production unit site, but in 2000 MISOLA was stocked in

at least one urban pharmacy, and the UCODAL products in some supermarkets.

the degree of fortification must be taken on trust.

Akerlof noted that this kind of asymmetric information, unless remedied, would drive the quantity sold to zero, since no buyer would be willing to pay the production cost of any given mixture, for fear that a cheaper recipe had been used instead. To support positive sales, sellers must build trust through brand identity, or else a third party must provide certification services. Both remedies involve real costs in communicating information.

The producer's remedy for asymmetric information-branding-involves signalling quality through high prices (Wolinsky, Bagwell and Riordan), conspicuous expenditure on packaging and advertising (Nichols), and often the two together (Milgrom and Roberts). ${ }^{3}$ Further quality signals may be given through the use of a high-markup retailer (Chu and $\mathrm{Chu}$ ). All of these strategies are costly to consumers, but help assure that producers have a strong interest in avoiding any lapse in quality (Klein and Leffler).

The third-party remedy for asymmetric information-certification-introduces a separate market for information about product quality, allowing consumers to see it directly and inducing suppliers to maintain quality at competitive prices (Caswell and Padberg).

\footnotetext{
${ }^{3}$ Of course, manufacturers can also make direct claims about quality in their labels, but as shown by Mojduszka and Caswell, products with measurably higher quality are not always so labeled. Firms may prefer other quality signals, for credibility among consumers and effectiveness in limiting price-reducing competition.
}

But not all markets suffering from asymmetric information can support a certification agency, if only because product testing has high fixed costs and requires a minimum market size to be cost-effective (Auriol and Schillizi). Furthermore, even if certification would be cost-effective, incumbent firms (or potential entrants who believe they can become incumbents) are likely to prefer the monopoly rents that accrue from brand identity, even though after voluntary certification is established they might have an incentive to adopt it and reduce prices (Crespi and Marette). For this reason, introducing certification requires concerted action by consumers or government, to document the demand for certification and initiate a credible program.

In this article, we test whether the magnitude of the price premium currently being paid by Malian families for branded infant foods includes a premium they would be willing to pay for a voluntary certification scheme. We use an innovative market-simulation experiment to elicit families' willingness-to-pay for quality information, and distinguish the value of certification from the premia paid for brand identity, packaging, and processing. We then compare that value of information to the estimated costs of introducing certification through laboratory testing, and find very large potential gains from certification. Our results imply that a credible certification system could sharply reduce the cost and increase the availability of high-quality fortified foods for six- to twenty-four-month-old children, providing substantial benefits for child health and well-being. 


\section{The Market for Complementary Foods in Mali}

The principal foods traditionally fed to infants in Mali are moni and rui, two kinds of porridge made from millet or sorghum flour, fortified with lemon, tamarind juice, sugar, sour milk, and other ingredients (Bauer et al.). ${ }^{4}$ Samples have been found to have very low caloric densities, around 35-45 kcal/100 g of dry matter (Bauer et al., Gerbouin-Rerolle and Chauliac), which is one-tenth of the caloric density in Cérélac or similar products (USDA, Lutter).

Our survey of mothers in Bamako, the capital city, found that about $50 \%$ of mothers use only rui, moni, or other family foods as complements to breastmilk, while $39 \%$ purchased some Cérélac or other industrial complementary food, and $11 \%$ used none at all. This is comparable to the nationwide results found in Mali's 1995/96 Demographic and Health Survey (DHS) (Trèche).

Initiatives to lower the cost and increase the availability of fortified foods were launched in Mali and across Africa in the 1980s (e.g., ICRISAT, 1990, 1992; Nicholson; Onofiok and Nnanyelugo). These included a wide variety of recipes and processing systems. The benchmark product, Nestlé's Cérélac, is a precooked mixture generally based on wheat and skim milk powder, plus sugar and micronutrients. The lowest-cost mixtures procured for the World Food Program (Dijkhuizen) or U.S. PL480 food aid (Marchione) are also precooked but are based on maize and soybeans, while products based on traditional infant foods in tropical countries have included many other processing techniques and ingredient lists. ${ }^{5}$

The approach taken by Mali's Food Technology Laboratory (FTL) was initially to promote a mixture of $80 \%$ pearl millet and $20 \%$ cowpeas, both of which are widely grown by smallholders for home consumption. The FTL is a unit of the Institut d'Economie Rurale (IER), the national agricultural research service, and initially it followed a traditional farmextension model, encouraging households to make the flour at home (Haïdara, 1989; Bauer et al.; Silva-Barbeau et al.). But few house-

\footnotetext{
${ }^{4}$ Moni is prepared as a family breakfast food with an uneven texture, of which adults and older children eat the denser granules, while infants consume only the more liquid base. Rui is prepared as a smooth porridge expressly for infants.

5 The oldest and most widely-known of the low-cost infant foods, Incaparina, was introduced in Guatemala in 1961 as a ready-tocook flour containing cottonseed (Scrimshaw, Wise, Tartanac).
}

holds took their advice: it turns out that cowpeas are difficult to store and so are not usually available throughout the year, while the processing effort required was prohibitive particularly in periods of peak agricultural labor demand. ${ }^{6}$ The FTL addressed the storage and processing constraints with mechanized production and plastic packaging, which also permitted the development of an improved recipe they called MILEG, composed of $67.6 \%$ millet, $20 \%$ cowpea, $5 \%$ maize, $5 \%$ raw sugar, $1.2 \%$ vanilla sugar, and $1.2 \%$ iodine salt.

Industrial production of MILEG began in February 1995, under contract to a newly established private food processing unit called the "Fabrique Alimentaire du Sahel" (FAS) in Bamako (Gerbouin-Rerolle and Chauliac). Significant sales were achieved in $1995,{ }^{7}$ but in 1996 demand declined and by May 1997 MILEG production had stopped completely. In 1997, another private firm, the "Unité de Transformation et de Conditionnement des Denrées Alimentaires (UCODAL)," emerged to replace FAS as a supplier of pre-packed complementary foods. They developed a broader range of products, eventually selling three different composite flours based on millet/maize/cowpea, sorghum/maize/cowpea, and rice/fonio/maize mixed with dried fish (Mariko). ${ }^{8}$ UCODAL had a production capacity of $500 \mathrm{~kg}$ per month in 1999, and like FAS almost all its sales were to public health services.

Meanwhile, other production and marketing techniques were under development elsewhere in Mali. In 1993, a French NGO operating at Diafarabé, in the remote Mopti region of northeastern Mali, began assisting a group of women to produce small batches of complementary foods by hand, on commission from local health services. This activity replicated a project that the same NGO had been operating since 1982 in Burkina Faso (Porter

\footnotetext{
${ }^{6}$ The procedure recommended by FTL involves hulling, winnowing, washing, drying, sifting, milling, and sifting again through a 0.6-mm mesh (Haïdara, 1990). Milling is particularly difficult in rural areas, where motorized mills are rare and grain must be pounded in a mortar using a pestle.

${ }^{7}$ In November 1995 output reached $95 \mathrm{~kg} / \mathrm{day}$, or $38 \%$ of the firm's theoretical production capacity. Although at one point MILEG was available at eighty pharmacies around Bamako, almost all actual sales were to public health and nutrition services. The firm's failings were analyzed in three donor-funded studies in 1996, which found that the firm had weak management and marketing systems, and that the product no longer met the nutritional norms expected from the original recipe (CECI, Keïta, Gerbouin-Rerolle and Chauliac).

${ }^{8}$ Fonio is a cereal grain produced in the Sahel, but not widely disseminated to other areas.
} 
and Shafritz). Their product, MISOLA, was composed of $60 \%$ millet, $20 \%$ soybeans, $10 \%$ peanuts, $9.5 \%$ sugar, and $0.5 \%$ salt (Bauer et al.). By 1999, the Association MISOLA had helped established similar production units in six other towns across the country. The most active group was at Kati, a suburban area of Bamako, which had been started in 1996 and by 1999 was producing up to eight $25-\mathrm{kg}$ batches per month, again with almost all sales to public health services.

Mali's three recent entrants to the infant food market (MILEG, MISOLA, and UCODAL) use a variety of recipes, technologies, and business models. Lutter and Huffman; Porter and Shafritz; and Caulfield, Huffman, and Piwoz document many similar kinds of experiences elsewhere. These various approaches are all technically capable of producing nutritionally appropriate foods, but consistently face quality control problems associated with asymmetric information between buyer and seller-so sales are generally constrained to large buyers who can observe production directly, or use laboratory testing to control quality. For example, the World Food Program (WFP) which contracts a large share of its complementary-food production to manufacturers in developing countries, uses independent registered surveyors to inspect those products and issue a Certificate of Fitness for Human Consumption (Dijkhuizen). The U.S. Food Grain Inspection Service conducts a similar testing program for products exported from the United States (Marchione). The Institute of Nutrition in Central America and Panama (INCAP), which developed Incaparina, is promoting a "Seal of Nutritional Excellence" to certify the quality of various foods produced by others (Tartanac). But the economic function of quality certification for infant foods has not yet been carefully analyzed, and the market for infant foods is, as illustrated for Mali in table 1 , often dominated by high-cost branded products despite the technical feasibility of low-cost production.

\section{The Feasibility and Cost of Certification in Mali}

Our work focuses on the demand for certification, but to measure that we must first describe how certification might be supplied. We provide only a rough sketch here, to generate the rudimentary cost estimates presented in our results section.
Auriol and Schillizi argue that certification programs are likely to be hardest to establish for small markets in poor counties. Mali as a whole is small (about 11 million people) and poor ( $\$ 240$ per person per year, by the World Bank Atlas method). The market for infant foods is particularly small (if only because it is needed for only a brief period of each person's life), and those who would benefit most from certification are particularly poor (notably those who cannot now afford enough Cérélac or other branded goods). It is understandable that certification has not yet emerged, but introducing it now could be both feasible and desirable.

The basic infrastructure needed is already present. There are two food laboratories equipped and staffed for testing nutrient density, one in the agricultural research service and one in the Ministry of Health, and there is a legal basis for using those laboratories in a certification program. ${ }^{9}$

We estimate the cost of certification based on a minimalist testing program, which would specify only whether the product's density of total protein, total energy, and total fats meets a standard similar to the levels in Cérélac. Micronutrients and pathogens are also important and could be tested, but the extreme growth deficits illustrated in figure 1 and the benefits of increased nutrient intake documented by Caulfield, Huffman, and Piwoz suggest that protein-energy malnutrition is a high priority. A focus on protein, energy, and fats also helps keep the tests simple and accurate, so relatively small samples and inexpensive laboratory services will yield a high level of certainty about the product. ${ }^{10}$

Our certification scheme uses only one standard, even though it would be possible to offer multiple standards or even to label the actual level of nutrient density. In the Malian context a single kind of food dominates the

\footnotetext{
${ }^{9}$ The laboratories are the Laboratoire de Technologies Alimentaires of the Institut d'Economie Rurale, and the Laboratoire Nationale de la Sante. The relevant legislation is law no. 92-013/ANRM adopted by Mali's National Assembly in August 1992, and order-in-council no. 92-235/P-RM signed by the government in December 1992. These directives established a Conseil National de Normalisation et de Contrôle de Qualité (CNNCQ), with a secretariat office in the Direction Nationale des Industries (DNI), and various technical committees. In July 2000, the CNNCQ secretariat at DNI expressed interest in convening a technical committee to implement quality certification for complementary foods, but had not yet done so. Current food safety controls are limited to large investment projects, which are reviewed before production begins with no provision for subsequent product testing.

${ }^{10}$ In our cost estimates, for example, we assume that the certifying agency tests one out of a thousand packages from each supplier, drawn at random from anywhere along the marketing chain.
} 
market, and few consumers have the education one might need to read and interpret detailed labels. (In our survey, $81 \%$ of mothers had never attended or not completed primary school.) Low education levels are also a reason to set the standard near Cérélac's nutrient density, even though other levels have been used elsewhere, simply to facilitate communication about what is being certified.

To keep the program simple and inexpensive, it could operate on a voluntary fee-forservice basis, and be offered to all potential producers. These conditions allow the program to be self-financing, since every firm that can meet the standard would then have an incentive to pay the fee and seek certification (Crespi and Marette). A voluntary fee-based system is also self-policing to some degree, since each certified firm has an incentive to monitor the testing of other firms, and the certification agency in turn has an incentive to seek demand for its services, thereby limiting the payoff from corruption that would characterize a mandatory standard. In effect, the voluntary fee-based approach induces producers and the certification agency to invest in a collective brand identity, and compete to provide that brand at lowest cost or with additional services to consumers. Examples of such voluntary quality-assurance schemes include the Underwriters' Laboratory (UL) listings and the International Organization for Standardization marks (such as ISO 9000). A voluntary certification scheme cannot offset all market failures, if only because certification itself is a natural monopoly, and also because there are externalities involved in anything concerning child health. But a voluntary scheme is likely to generate a substantial share of the potential benefits from introducing certification services, and imposing mandatory labeling would introduce incentives for fraud that are unlikely to be easily controlled in the Malian context.

The cost estimates we use are detailed in the data and results section below, and compared to consumers' willingness-to-pay. A crucial feature of the analysis is that it concerns the demand and supply for certification itself, rather than for any particular product. And since the certification refers to nutrient density, rather than ingredients or processing style, potential suppliers can meet the standard with a variety of recipes and techniques, each of which would have different observable characteristics and different prices. The certification process would work similarly for mechanized producers such as UCODAL, as for artisanal production along the MISOLA model, and other improvements on traditional infant-food recipes.

In all these cases, qualities other than nutrient density such as contamination or palatability can be judged by consumers, based on observable characteristics, taste tests, and the child's immediate response. The goal of certification is not to substitute for consumer awareness, but to complement it by signaling that producers have not lowered their costs by increasing the proportion of low-density cereals in the product mix. In this way, it provides an incentive-based intervention, supporting a more competitive market and encouraging the entry of small-scale producers as suggested by Unnevehr and Hirschhorn.

\section{Methodology and Design of the Experiment}

Our approach follows the standard Lancastrian model of consumer choice, analyzing product demand in terms of individual attributes (Lancaster, 1966; 1971). This approach allows a researcher to identify the demand for a particular attribute, by comparing the demand for products containing that attribute with similar ones that do not. Many recent studies use this approach to measure the value of food quality and safety improvements (e.g., Caswell; Holland and Wessels; Unnevehr and Villamil).

Lancaster's approach posits that consumers seek to maximize a utility function defined in terms of the consumption of characteristics, rather than goods:

$$
U=U\left(x_{01}, x_{02}, \ldots, x_{0 m}\right)
$$

where $x_{0 j}$ is the amount of the $j$ th characteristic consumed. Characteristics are derived from goods, with the simplest specification being linear:

$$
x_{0 j}=\sum_{i} x_{i j} q_{i}: j=1,2, \ldots, m
$$

where $q_{i}$ is the amount consumed of the $i$ th good consumed, and $x_{i j}$ is the amount of characteristic $j$ in each unit of good $i$.

In our analysis of nutritional certification, a particular kind of infant food $i$ is taken to have as characteristics both nutrients (e.g., attribute " $p$ " for protein) and signals about nutrients (e.g., attribute "c" for certainty). The consumer values the total amount of certainty she obtains ( $x_{0 c}$ in equation (1)), as well as nutrients $\left(x_{0 p}\right)$, rather than the quantity of the 
good itself $\left(q_{i}\right)$. More certainty, over a larger quantity of food purchased, is better. But consumers cannot buy attributes directly. They must buy them in goods that are fixed bundles of attributes, to which prices and the budget constraint apply:

$$
\sum_{i=1}^{n} p_{i} q_{i}=I
$$

where $p_{i}$ is the price of good $i$ and $I$ is income.

In terms of observable data on goods, the solution to this problem for a well-behaved utility function is a set of $n$ ordinary demand functions (Ladd):

$$
q_{i}=q_{i}\left(p_{1}, \ldots, p_{n}, I, x_{11}, \ldots, x_{n m}\right) .
$$

Thus, for the case of certification, the consumer's certainty about nutrients in a particular good $\left(x_{i c}\right)$ may be just as important as its actual level of nutrients $\left(x_{i p}\right)$ in determining the price $\left(p_{i}\right)$ at which the consumer is willing to buy a unit of it $\left(q_{i}\right)$.

Empirically, if there is enough variation in characteristics across goods, and if expenditures on the relevant goods are a small portion of $I$, an estimate of marginal willingness-topay for unit changes in each characteristic may be obtained from market data on demand for each good, associating differences in the $x_{i j}$ parameters with shifts in the $q(p)$ demand curve. There is a large literature of such "hedonic" regressions (e.g., Van Ravenswaay and Hoehn). In our setting, certification is not being provided in the market (yet), so we use a market experiment to elicit preferences. We seek to isolate willingness-to-pay for certification from other attributes, and so ask our respondents to choose among a range of products, only one of which has our experimental certification.

To elicit preferences that are consistent with market behavior, a standard approach is to use Vickrey auctions, in which bids are sealed and the highest bidder is awarded the product at the second-highest bidder's price. Prominent applications to experiments involving food quality include Shogren et al., Hayes et al., and Melton et al. Such studies require the experimenter to assemble the participants, instruct them, record their bids, make comparisons, and then award the products.

To elicit preferences in a less cumbersome manner than the Vickrey auction, we were inspired by Binswanger to construct an exchange process that would also be preferencerevealing, but could be done on an individual basis with minimal set-up time. In the
Binswanger setting, respondents were offered a choice of gambling lotteries to reveal their risk-aversion. Here, we offered a choice of infant foods, that differed only in respect to the characteristics of interest.

\section{Experimental Procedure}

To initiate the experiment, we set up a table under a shelter near an outdoor food market. On the table was a standard 400-g can of Cérélac, a sealed plastic bag of an unknown powder with a printed label, an open container of a similarlooking powder, and bags of raw millet, maize, cowpeas, peanuts, and sugar. Further quantities of these goods were stacked behind the table.

The presence of the table attracted a crowd of people interested in infant foods, and if necessary an assistant circulated elsewhere in the marketplace to tell others about the experiment. People were told that mothers accompanied by a child under two years of age could participate in a kind of survey, for which they would be given a can of Cérélac or something else of similar value. Everyone approaching the table recognized the Cérélac, and almost all were interested in obtaining it for their child. Indeed identical cans were available throughout the local area, at a price of 1400 or 1500 FCFA depending on the type of shop (about $\$ 2.30$, or roughly a day's wage for unskilled labor).

We conducted the experiment at a random set of ten Bamako shopping areas, where self-selection attracted a subset of shoppers interested in acquiring Cérélac. At each site we interviewed twenty-five women accompanied by their infants, selected by virtue of being the first to arrive, providing a total sample size of 250 mothers from random parts of the city. Ten respondents failed to complete the experiment, leaving a final sample size of 240 .

The survey consisted of a short questionnaire, followed by a series of choices through which they could trade the Cérélac for something else. (The survey form listing these choices is available from the authors on request.) Since each respondent made many choices, actually giving them each choice would have quickly satiated their potential demand, and exhausted our research budget. We therefore recorded each choice on a card, put the cards in a box, and then invited the respondent to draw one of those cards at random from the box when they were finished to determine what they would actually take home. Thus, 
participants knew they would obtain either the can of Cérélac, or something else of similar value.

The substitutes we offered for the Cérélac were a powder in sealed bags, a powder in open bags, and raw grains. The sealed bags were labeled "Certilac," with a drawing of a well-fed infant, and text detailing the sponsorship of the Institut d'Economie Rurale (IER), Mali's national agricultural research service. ${ }^{11}$ Respondents were told that the label meant that IER staff had inspected the product, and certified it to be similar to Cérélac in nutritional value, although it did not have the same ingredients. IER is well known in the city of Bamako, if only because its name appears on the side of numerous vehicles. Indeed, one such vehicle was parked next to the experiment site, which helped ensure that respondents recognized the authenticity of the claim and its connection to an established authority. ${ }^{12}$

The powder in open bags looked slightly different than the Certilac, and had no label or other mark. We called it the "anonymous" product, and made no particular claims about it. The raw grains were well known to all consumers, since they are in routine use for grinding and cooking at home.

In fact, the "Certilac" was produced by UCODAL and relabeled by us. The anonymous powder was MISOLA, obtained from the production unit near Bamako. And the raw grains were provided in the proportions advocated as a local infant food by Trèche, namely millet and maize $(28.4 \%$ each), cowpea $(18.6 \%)$, groundnuts $(11.1 \%)$, and sugar $(13.5 \%) .{ }^{13}$

The respondent's first choice was between the $400 \mathrm{~g}$ can of Cérélac and a $400 \mathrm{~g}$ bag of Certilac. The interviewer then increased the quantity of Certilac being offered in exchange for the Cérélac, in increments of $100 \mathrm{~g}$, and at each increment the respondent's willingnessto-swap was recorded on a card and dropped in the lottery box. Respondents were told-and could see on the recording sheets- that a max-

\footnotetext{
${ }^{11}$ We sealed the Certilac bags, and not the anonymous product, because we considered sealing to be a key characteristic of a certified product - sealing assures the consumer that the product being purchased is the same one that was sampled and tested, while lack of sealing conveys the idea of a generic product for which the only quality control is the consumer's direct observation.

${ }_{12}$ The IER logo is not actually associated with any commercial product, but it is known as the source of several widely-used crop seed varieties.

${ }^{13}$ In fact, Trèche recommends a recipe with $13.2 \%$ sugar and $0.3 \%$ of a vitamin/mineral supplement. We did not include the supplement and rounded up the sugar content.
}

imum of five increments would be offered. Respondents could therefore switch from Cérélac to Certilac when offered 400, 500, 600,700, 800, or $900 \mathrm{~g}$ of Certilac in exchange for the $400 \mathrm{~g}$ of Cérélac. The quantity at which they switched forms the first observation for our study.

The second set of choices begins with an offer to swap the chosen quantity of Certilac for an equal quantity of the anonymous product, or up to four $100 \mathrm{-g}$ increments of the anonymous product in addition. As before, the respondent's choice was recorded on a card and mixed with their other choices, and the quantity of anonymous product finally accepted provides our second data point. It ranges from 0 to $400 \mathrm{~g}$ larger than the respondent's quantity of Certilac.

To complete the experiment we continued with a third set of choices, swapping the anonymous product for increasing quantities of raw ingredients, in fixed proportions as noted above. Here we pre-specified the range of quantities from 4 to $8 \mathrm{~kg}$ of the mixture, in 1$\mathrm{kg}$ increments. Again we recorded the quantity needed to induce a swap as our data point.

\section{Interpretation of Results}

We use the respondent's choices to infer their willingness-to-pay for individual characteristics, interpreting each decision as an expression of preference for one bundle of characteristics over another. In the notation of equations (1) through (4) above, given our step-wise increments, choosing $q_{k}$ quantity of good $k$ over $q_{i}$ quantity of good $i$ implies that the vector of characteristics $\left(\boldsymbol{x}_{k}\right)$ provided by $q_{k}$ gives equal or greater utility than the characteristics $\boldsymbol{x}_{i}$ provided by $q_{i}$ :

$$
U\left(\boldsymbol{x}_{i}\right) \leq U\left(\boldsymbol{x}_{k}\right) .
$$

We recover willingness-to-pay levels by duality, interpreting utility maximization in terms of expenditure minimization at the given levels of utility, so that

$$
e\left(\boldsymbol{p}, U^{i}\right) \leq e\left(\boldsymbol{p}, U^{k}\right)
$$

where $e$ is minimized expenditure at the consumer's (unknown) vector of goods prices $p$ and level of utility $U^{i}$ or $U^{k}$ associated with the quantities $q_{i}$ and $q_{k}$ respectively. In other words, a respondent's choice of $q_{k}$ over $q_{i}$ implies that $q_{k}$ is worth more money to them. Assuming separability from all other goods we can isolate expenditure on these two goods:

$$
p_{i} \cdot q_{i} \leq p_{k} \cdot q_{k}
$$


and then solve for the implicit price or willingness-to-pay for good $k$ in terms of the price of $\operatorname{good} i$ and the two quantities:

$$
p_{k} \geq p_{i} \cdot \frac{q_{i}}{q_{k}}
$$

where $p_{k}$ is the unknown willingness-to-pay for the good received in exchange for good $i, q_{k}$ is the quantity of it received, and $p_{i}, q_{i}$ are the price and quantity of the good exchanged for it. In our case we have three $q_{i} / q_{k}$ ratios, derived from the initial 400-g quantity of Cérélac and the switching-point quantities of Certilac, anonymous product, and raw ingredients. We use the market price of Cérélac and apply equation $\left(7^{\prime}\right)$ successively to compute willingness-to-pay for each product, and then compute the value of certification as the premium offered for Certilac over the anonymous product. The same data also reveal willingnessto-pay for packaging and the brand identity (in the premium paid for Cérélac over Certilac), and willingness-to-pay for processing (in the premium paid for the anonymous product over the raw ingredients).

Our procedure allows us to infer willingnessto-pay from a sequence of simple choices, rather than the more complex bidding process of a Vickrey auction. The procedure has important limitations when estimating willingnessto-pay for each product ( $p^{*}$ and $p$ ), and is most useful for estimating the differences between products $\left(p^{*}-p\right)$ that are used for our final results. First, the overall level of each respondent's willingness-to-pay values is set by the market price of Cérélac, irrespective of that respondent's actual willingnessto-pay for that product. ${ }^{14}$ Second, as noted above, the use of step-wise increments and the imposition of lower and upper limits to the choices offered truncates the distribution of possible responses. Finally, a more subtle kind of measurement error arises due to the lottery structure of the exercise, as detailed below.

The use of sequential choices and a lottery structure introduces some incentives for strategic bidding away from the relative utilities shown in equation (5) above, because the respondent's choice of whether to accept

\footnotetext{
${ }^{14}$ Our pre-experiment survey found that $39 \%$ of the respondents actually buy Cérélac, implying that their willingness-to-pay for it is equal to or greater than the market price of FCFA1500. The remaining $61 \%$ who do not buy Cérélac presumably have a lower willingness-to-pay for it, but they might be able to resell the tin for close to its market price if they so chose.
}

each offer determines whether a higher offer is made. ${ }^{15}$ To derive the incentives facing the respondent, we need to consider the utility they derive from the entire lottery, rather than just the utility derived from each good. Simplifying the problem to consider the respondent's choice between two of the goods, the expected value of the resulting lottery is

$$
E[U(L)]=\frac{n}{n+1} U\left(q_{i}\right)+\frac{1}{n+1} U\left(q_{k}\right)
$$

where $q_{k}$ in turn can be broken down into the initial offer $\left(z_{k}\right)$, the step-wise increment $\left(s_{k}\right)$, and the number of increments $(n)$

$$
q_{k}=z_{k}+n \cdot s_{k} .
$$

The choice variable in this problem is $n$. For example, if the respondent accepts the initial offer, then $n=0$ and the lottery is a sure bet to win that offer. If the respondent holds out for one increment, then $n=1$ and the lottery is a fifty-fifty bet to win the opening stake or the initial offer plus one increment. If she holds out for two increments, she has a two-thirds chance to win the opening stake and a onethird chance to win the initial offer plus two increments, and so forth. An expected-utility maximizing person would hold out for an additional increment as long as

$$
\frac{\partial E[U(L)]}{\partial n} \geq 0
$$

which simplifies to

$$
U\left(q_{i}\right)+(n+1) U_{k} s_{k} \geq U\left(q_{k}\right) .
$$

Where $U_{k}$ is the derivative of $U$ with respect to $q_{k}$ (that is, the marginal utility of the second good). Thus the optimal choice in the lottery context is not quite the same as the optimal choice in the once-off comparison presented in equation (5). Instead of equalizing the utility levels $U\left(q_{i}\right)$ and $U\left(q_{k}\right)$, the lottery context gives the respondent an incentive to hold out for a higher $U\left(q_{k}\right)$, by an amount that depends on the number of lottery prizes $(n+1) \times$ the marginal utility of that good $\left(U_{k}\right) \times$ the size of the increment being offered $\left(s_{k}\right)$.

Abstracting from integer constraints, equation $\left(9^{\prime}\right)$ would hold with equality as the firstorder condition for optimization, for which the second-order condition is

\footnotetext{
15 The authors are grateful to an anonymous reviewer for encouraging us to pursue this question.
} 
Table 2. Summary Statistics for Willingness-to-Pay Results

\begin{tabular}{lrcrr}
\hline & \multicolumn{4}{c}{ WTP (FCFA per 400 g) } \\
\cline { 2 - 5 } & Average & Standard Deviation & Minimum & Maximum \\
\hline WTP by product & & & 667 & 1500 \\
$\quad$ Certilac & 1159.83 & 357.77 & 462 & 1500 \\
$\quad$ Anonymous product & 704.59 & 210.36 & 75 & 150 \\
$\quad$ Raw ingredients & 119.14 & 35.07 & & \\
WTP for Premium $^{\text {a }}$ & & & 0 & 1038 \\
$\quad$ Certification (anon. to cert.) & 455.24 & 251.22 & 312 & 1425 \\
$\quad$ Processing (raw to anon.) & 585.45 & 213.97 & & \\
\hline
\end{tabular}

Source: Survey data.

${ }^{\text {a }}$ Values shown are the differences in WTP between the anonymous product and Certilac (for certification), and between the raw ingredients and the anonymous product (for processing). Using a $t$-test on matched samples, the $95 \%$ confidence intervals around the point estimates are $(423,487)$ and $(558,613)$ for certification and processing respectively.

$$
\begin{aligned}
& \frac{\partial^{2} E[U(L)]}{\partial n^{2}} \\
& =\frac{-2}{(n+1)^{3}}\left[U\left(q_{i}\right)-U\left(q_{k}\right)+(n+1)\right. \\
& \left.\quad \times U_{k} s_{k}-\frac{1}{2}(n+1)^{2} U_{k k} s_{k}^{2}\right]
\end{aligned}
$$

At the extremum where $\left(9^{\prime}\right)$ holds exactly, $\left(9^{\prime \prime}\right)$ is negative as long as $U_{k k}$, the second derivative of $U$ with respect to the second good, is also negative.

In our set-up, since each refusal brings a larger offer, respondents can trade-off the possibility of winning the larger prize against the declining probability of winning it. From equations $\left(9^{\prime}\right)$ and $\left(9^{\prime \prime}\right)$ we see that respondents who derive positive but diminishing marginal utility from the good being offered can maximize their expected utility from the lottery by holding out for a somewhat larger offer than the one that equalizes their utility levels from the goods themselves. Respondents who engage in this kind of strategic bidding would understate their preference for the second in each pair of goods, and hence overstate the premium they would pay for the difference. The experimental results presented below give some indication of the relative importance of these strategicbidding effects in our simple framework, but more robust evidence would require further experiments comparing respondents' choices in this set-up with their behavior in Vickreytype auctions.

\section{Data and Results}

Our survey data consist of market prices and respondents' choices, from which we compute willingness-to-pay for certification. We then construct a rough budget for a proposed certification service, which we combine with the demand data to compute the economic gain from introducing certification to the market.

Table 1 presents the observed prices for infant foods in Mali. Market-share data are not available, but the dominant product, packaging size and retail channel is the $400-\mathrm{g}$ can of wheat-based Cérélac sold in shops. Thus the initial quantity $\left(q_{i}\right.$ in equation $\left.\left(7^{\prime}\right)\right)$ is $400 \mathrm{~g}$, and the initial price $\left(p_{i}\right)$ is 1500 FCFA.

Table 2 presents summary statistics on respondents' choices in terms of willingnessto-pay, using equation $\left(7^{\prime}\right)$ to convert their switching-point quantities $\left(q_{k}\right)$ into monetary terms. (The full set of data is available from the authors on request.) Each individual's willingness-to-pay for each product is also used to compute the premium they were willing to pay for each set of additional attributes. Their WTP for certification is computed as the difference between their WTP for Certilac and for the anonymous product, while their WTP for processing is the difference between their WTP for the anonymous product and for the raw ingredients.

Before reviewing our WTP estimates, it is important to examine the data for evidence of strategic bidding and other biases arising from our experimental design. A first concern is whether the upper and lower bounds were appropriately chosen. ${ }^{16}$ It turns out that a very large proportion of the data (579 out of 720 switching points, or $80 \%$ ) were limit observations, and each of the three switching-point distributions were truncated in different ways.

\footnotetext{
16 The authors thank an anonymous referee for encouraging us to focus on this issue.
} 
In the initial choice, exchanging Cérélac for Certilac, $45 \%$ of respondents were at the lower bound and $29 \%$ were at the upper bound. If the underlying distribution were symmetrical, truncating it in this way would impose an upward bias on the observed mean quantity of Certilac chosen in exchange for the Cérélac, leading to a downward bias in the estimated willingness-to-pay for Certilac. In the second choice, exchanging Certilac for the anonymous product, only $1 \%$ of observations were at the lower bound, and $78 \%$ were at the upper bound. With a symmetrical underlying distribution, truncating the distribution in this way would impose a downward bias on the mean quantity of anonymous product, leading to an upward bias in the estimated willingness-topay for it. Finally in the third choice, exchanging the anonymous product for the raw ingredients, $53 \%$ of observations were at the lower bound, and $35 \%$ were at the upper bound. Here the bounds imposed an upward bias in the mean quantity of raw ingredients, and a downward bias in the estimated willingnessto-pay for them. Our principal concern is not the levels of WTP, but rather the WTP premium offered for Certilac over the anonymous product. Since imposing the limits probably led respondents to understate their WTP for Certilac and overstate their WTP for the anonymous product, on average the WTP for certification is likely to have been underestimated. In hindsight the upper and lower bounds were much too restrictive, but the pattern of truncation suggests that we can proceed with our results, recognizing that they are likely to understate the principal result of interest. Furthermore, since two of the three choices were disproportionately made at the lower bound, it seems unlikely that the incentive for strategic bidding to higher switching points identified in equation $\left(9^{\prime}\right)$ had very much influence on our results.

From table 2, we find that the WTP for certification averaged 455 FCFA per $400 \mathrm{~g}$ With caution considering the truncation biases discussed above, we can also use these data to perform a very rough decomposition of the price paid for Cérélac (1500 FCFA per $400 \mathrm{~g}$ can) into consumers' willingness-to-pay for four distinct attributes. Less than a tenth of the total price paid is willingness-to-pay for equivalent ingredients alone (119 FCFA). Over a third is willingness-to-pay for basic processing (about 585 FCFA), just under a third is for quality information of the sort provided by the Certilac label (455 FCFA), and the balance (about
340 FCFA) is paid for other attributes including better processing and ingredients (perhaps particularly the skim milk powder, which is a high-cost but flavorful source of fats and protein), more durable packaging, and also residual confidence above what could be provided by a certification agency. Introducing certification would clearly not eliminate the value of branding a differentiated product, but it could have significant impact on it.

To compute the economic gain from introducing certification, we need to know the costs of doing so. Since there are large investments and indivisibilities involved, the average cost depends on the number of units certified. To guesstimate the cost schedule, we took an engineering approach with the following assumptions. One unit of each thousand sold would be sampled, and purchased at an average cost of 220 FCFA for whatever was the smallest available packaging size of each kind of product. The unit cost of testing each sample is 3,300 FCFA, which is the current cost quoted by the Laboratoire Nationale de la Santé for the three macronutrient density tests. Indivisible staff costs were estimated to be 1 million FCFCA for each increment of fifty bags sampled per month. Transport costs, for the staff to visit markets and production sites, were estimated to be 600,000 FCFA for each increment of twenty bags sampled per month. And most importantly, a continuous expenditure of 10 million FCFA per month was allotted for advertising and marketing to establish credibility. The result is a downwardsloping cost curve, plotted on figure 2. (There might be increasing marginal costs eventually, if a very large sampling program were to require additional laboratory infrastructure, but this does not seem likely given the available capacity at existing labs.)

To determine the number of units that are likely to be certified, we guesstimated as follows. First we assumed that only residents of Bamako would purchase certified products, so as to be conservative in our estimate. From file data of the Direction Nationale de la Statistique, we computed that there were 49,598 children between the ages of six to twenty-four months in the city of Bamako in 1999. If the average child consumes $100 \mathrm{~g} /$ day (Dijkhuizen), they need about eight units of $400 \mathrm{~g}$ per month. To ask what proportion might consume a certified food, we took as our low estimate the share that now receives at least some Cérélac, and as our high estimate the share that now receives any kind of additional food. From our 


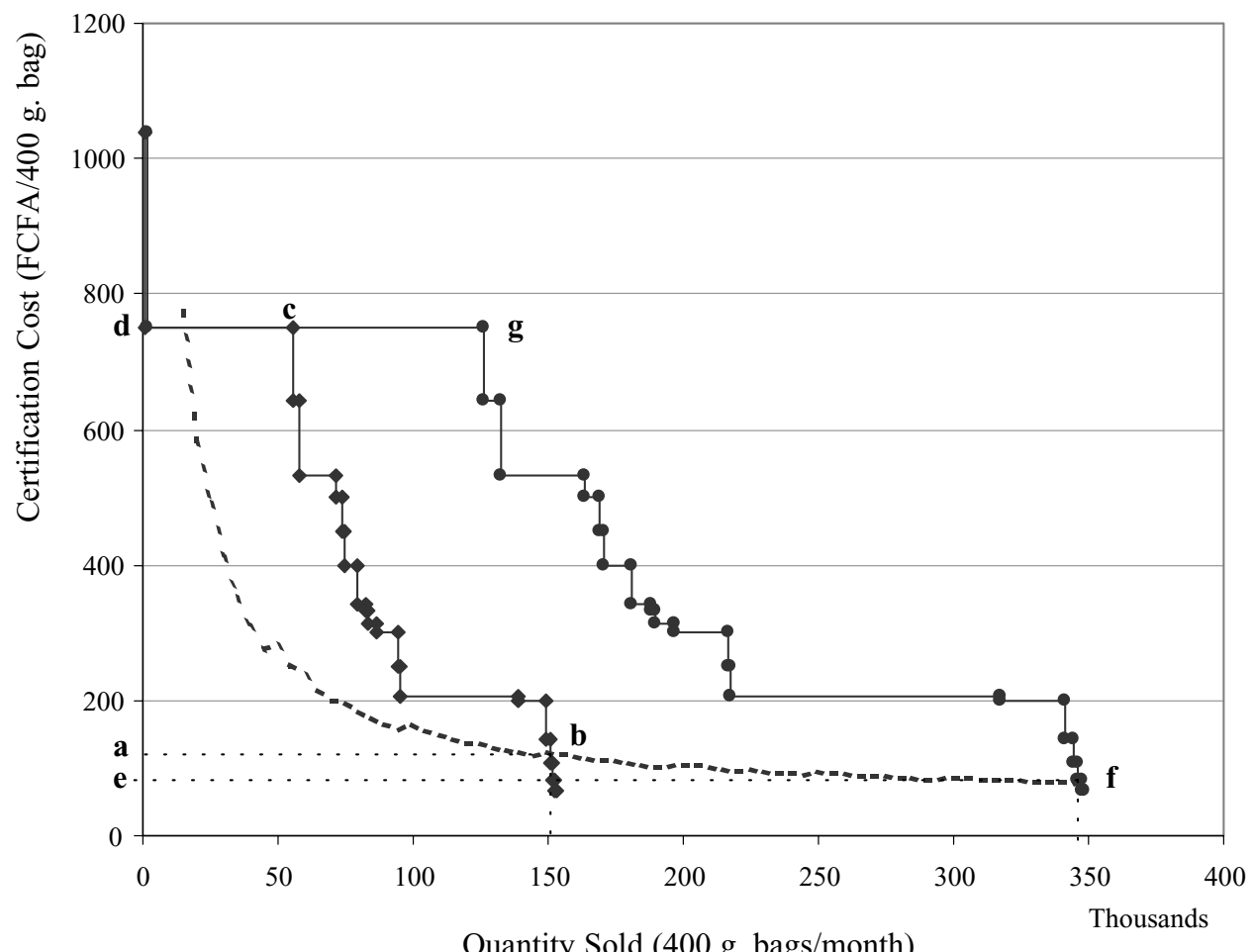

$\longrightarrow$ Demand-Case $1 \longrightarrow$ Demand-Case 2 - - - - Cost of Cert.

Figure 2. Estimated demand and supply curves for certification

pre-experiment survey, these data are 39 and $89 \%$ respectively, with $11 \%$ receiving no food other than breastmilk. The result is a "low" and a "high" estimate of total potential market size that is 154,746 and 353,138 units per month respectively.

We use the low and high market-size estimates to estimate the economic value of certification using two distinct approaches. The first approach uses the distribution of responses to construct demand curves and compute low and high estimates of economic surplus, while the second approach uses average responses to compute a low and high estimates of average net benefits.

For the demand-curve approach, we ask what proportion of the total potential market would actually be met, given that some of our respondents might have a WTP for certification below its estimated cost, and hence not buy the certified products even if it were available. Using the cumulative distribution of WTP levels, we computed the cumulative share of the total market whose WTP was below each threshold. The resulting two demand curves are plotted on figure 2. Where each demand curve meets the cost-of-certification schedule is the projected equilibrium quantity to be certified each month, also shown on figure 2. Furthermore, the area below each demand curve is the consumer surplus associated with introducing certification, from which we subtract the total cost of certification to obtain an estimate of net benefits, as shown in table 3 .

The cost-benefit approach is based on the idea that variation in WTP across consumers is measurement error, so the data we should use is the sample mean. In this case we interpret the mean as the WTP of a representative consumer, which is well above the average cost of certification, implying that effective demand would extend to the total potential market size. The difference between average WTP and average cost over that quantity market size can then be interpreted as net economic benefit, in a benefit-cost approach. These computations are also shown in table 3 .

It turns out that the economic-surplus and benefit-cost estimates of social gains are nearly identical. (This is because the distribution 
Table 3. Estimated Consumer Surplus and Net Economic Benefit from Certification

\begin{tabular}{|c|c|c|c|}
\hline & & Case 1 & Case 2 \\
\hline \multicolumn{4}{|c|}{ Consumer Surplus Approach } \\
\hline Equilibrium quantity certified & (400-g bags/month) & 150,000 & 345,000 \\
\hline Consumer surplus & (FCFA/month) & $70,271,984$ & $160,643,838$ \\
\hline Total cost of certification & (FCFA/month) & $18,728,000$ & $26,614,400$ \\
\hline Net economic surplus gain & (FCFA/month) & $51,543,984$ & $134,029,438$ \\
\hline Net economic surplus gain & (US\$/year) & 951,581 & $2,474,390$ \\
\hline \multicolumn{4}{|c|}{ Cost-Benefit Analysis Approach } \\
\hline Average WTP for cert. & (FCFA/400-g bag) & 455 & 455 \\
\hline Average cost of cert. & (FCFA/400-g bag) & 121 & 81 \\
\hline Net economic benefit/bag & (FCFA/400-g bag) & 334 & 374 \\
\hline Net economic benefit/month & (FCFA/month) & $51,713,454$ & $132,138,264$ \\
\hline Net economic surplus gain & (US\$/year) & 954,710 & $2,439,476$ \\
\hline \multicolumn{4}{|c|}{$\begin{array}{l}\text { Notes: The consumer surplus approach uses the distribution of WTP to infer the demand curve, interpreting each respondent's WTP as their } \\
\text { marginal utility of certification, summed over all consumers up to where marginal utility equals the average cost of certification which determines } \\
\text { the equilibrium quantity certified. } \\
\text { The cost-benefit analysis approach uses only the mean WTP, interpreting each respondent's WTP as an error-prone measure of a represen- } \\
\text { tative consumer's WTP, and specifies the average cost of certification to be that required to meet total estimated market size. } \\
\text { The market size estimates are based on an estimate of } 49,598 \text { children aged six to twenty-four months in Bamako, each of whom potentially } \\
\text { consumes } 8 \times 400 \mathrm{~g} \text { of Certilac-quality food per month. Case } 1 \text { assumes that only } 39 \% \text { would substitute (the proportion now consuming Cérélac), } \\
\text { and case } 2 \text { assumes that } 89 \% \text { would substitute (those now receiving any complementary food). }\end{array}$} \\
\hline
\end{tabular}

of WTP happens to be nearly symmetrical.) Introducing the certification program generates a net gain of more than 51 million FCFA per month (or almost one million dollars per year) in the low-demand scenario, and over 130 million FCFA per month (U.S.\$2.4 million per year) in the high-demand scenario.

These estimates, and the data in figure 2, show WTP levels well above our estimated cost levels. Thus many sorts of certification program are likely to be able to recover their costs in fees, and still provide net social benefits. But to make the certification program as beneficial as possible, it would be very important for it to be designed so as to reach the broadest possible market size, and hence also be able to charge lower fees, leaving larger net benefits for families and children.

For a given service, market size can extend only as far as the marginal purchaser's WTP exceeds the certification agency's average costs. We found that essentially all respondents expressed a WTP above $200 \mathrm{FCFA} / \mathrm{bag}$. On the cost side, we consider our cost estimates to be on the high side, including a very stringent testing rate (one per thousand) and large advertising expenditure (about U.S. $\$ 17,000$ per month, in a small city with very low-cost media). Yet costs falls rapidly over the relevant range, falling below $200 \mathrm{FCFA} / \mathrm{bag}$ at a relatively small market size of 75,000 bags/month, and falling below $100 \mathrm{FCFA} / \mathrm{bag}$ at 215,000 bags/month. Knowing the WTP data, it seems very likely that a testing program could be designed to reach a large market at reasonable cost-possibly below $100 \mathrm{FCFA} / \mathrm{bag}$ - thereby very substantially improving the market for infant foods.

\section{Conclusions}

This article uses an innovative market experiment to let mothers trade a well-known infant food for alternative products, and thereby reveal their willingness-to-pay for a variety of infant-food characteristics. We find that the very large premium currently being paid for heavily advertised brands reflects in part a high willingness-to-pay for information about product quality, which could perhaps be provided more efficiently by a laboratory testing and product certification service.

The market experiment used to elicit willingness-to-pay for certification asks mothers to trade one product for another, using the relative quantities of the two products to infer the mother's willingness-to-pay for each product's attributes. The process involves a series of simple choices between two alternatives, and is therefore much simpler to implement than Vickrey auctions. Our specific implementation suffered from overly narrow limits on respondent's choices, but this is likely to have led to an unambiguously downward bias in the calculated willingness-to-pay for 
certification. Our approach also introduces some strategic-bidding incentive for respondents, but there is little evidence of its importance in this context. In sum, the experimental method we introduce in this article has some potential to be used elsewhere, subject to careful setting of upper and lower bounds, and it offers interesting opportunities to test respondents' tendency to bid strategically by comparing their choices in this setup with their choices in a Vickrey auction.

Our estimate of the economic value of certification is that Bamako mothers' average willingness-to-pay for information about infant-food quality is approximately FCFA 450 per 400 -g unit $(\$ 1.75 / \mathrm{kg})$, which is about four times our estimate of the cost of laboratorybased certification. Given our estimate of total market size, these data suggest that introducing certification services would generate economic-surplus gains in the city of Bamako of the order of one million dollars annually, and perhaps as high as \$2.4 million annually. These benefits would be highly targeted to families with infants. If spread uniformly across the city's 50,000 infants of complementary-feeding age, the lower estimate of net economic benefits represents a gain of $\$ 20$ per child, per year-enough for their families to buy each one at least a month's supply of high-quality food.

A certification program for infant foods can be seen as a market-based intervention to improve nutrition and child health. Introducing certification facilitates the entry and expansion of new and small-scale agroprocessing enterprises, by providing a collective brand name under which the quality of numerous products would be advertised to the public and enforced through laboratory testing.

With willingness-to-pay for certification well above its cost, the study finds that certification could be introduced on a self-financing, fee-for-service basis. To introduce certification, the national standards authority would need to establish sampling and testing protocols, authorize a laboratory to collect fees for this service, and authorize firms meeting the criteria to use a standard certification logo at the point of sale and in product packaging. Given the importance of infant nutrition for public health, government and foreign-aid donors might want to subsidize the process, paying some of the project's start-up costs and laboratory fees. And since similar problems arise in virtually every low-income country, it is very likely that infant-food certification could be done on a regional or even global basis even more cost-effectively than for a small city like Bamako.

\section{[Received April 2001; final revision received September 2002.]}

\section{References}

Akerlof, G.A. "The Market for 'Lemons': Quality Uncertainty and the Market Mechanism." Quart. J. Econ. 84(August 1970):488-500.

Auriol, E., and S. Schillizi. "Quality Signaling through Certification. Theory and an Application to Agricultural Seed Markets." IDEI Toulouse, France (www.idei.asso.fr), 2000.

Bagwell, K., and M.H. Riordan. "High and Declining Prices Signal Product Quality." Amer. Econ. Rev. 81(March 1991):224-39.

Bauer, A. et al. "Complementary Food Improvement and Constraints on its Acceptance by Rural Women." Consultation Report to Novartis Foundation for Sustainable Development. Basel, Switzerland: Novartis Foundation, 1997.

Binswanger, H.P. "Attitudes toward Risk: Experimental Measurement in Rural India." Amer. J. Agr. Econ. 62(August 1980): 395-407.

Brown, K.H., and C.K. Lutter. "Potential Role of Processed Complementary foods in the Improvement of Early Childhood Nutrition in Latin America." Food and Nutr. Bull. 21(March 2000):5-10.

Brown, K.H., K. Dewey, and L. Allen. "Complementary Feeding of Young Children in Developing Countries: A Review of Current Scientific Knowledge.” WHO/NUT/98.1. Geneva: World Health Organization, 1998.

Caswell, J.A., and D.I. Padberg. "Toward a More Comprehensive Theory of Food Labels." Amer. J. Agr. Econ. 74(May 1992):460-68.

Caswell, J.A., ed. Valuing Food Safety and Nutrition. Boulder, CO: Westview, 1995.

Caulfield, L.E., S.L. Huffman and E.G. Piwoz. "Interventions to Improve Intake of Complementary Foods by Infants 6 to 12 Months of Age in Developing Countries: Impact on Growth and on the Prevalence of Malnutrition and Potential Contribution to Child Survival." Food and Nutr. Bull. 20(June 1999):183-200.

CECI. "Projet d'Appui à la Promotion de la Farine de Sevrage MILEG." A Report Submitted to CIBA-GEIGY, Bamako, Mali, 1996.

Chu, W., and W. Chu. "Signaling Quality by Selling through a Reputable Retailer: An Example of Renting the Reputation of Another Agent." Mktg. Sci. 13(Spring 1994):177-89. 
Crespi, J.M., and S. Marette. "How Should Food Safety Certification be Financed?" Amer. J. Agr. Econ. 83(2001):852-861.

Darby, M.R., and E., Karni. "Free Competition and the Optimal Amount of Fraud," J. Law and Econ. 16(April 1973):67-88.

Dijkhuizen, P. "Processed Complementary Foods in the World Food Programme." Food and Nut. Bull. 21(March 2000): 62-4.

Fox, J.A., J.F. Shogren, D.J. Hayes, and J.B. Kliebenstein. "Experimental Auctions to Measure Willingness To Pay for Food Safety." Valuing Food Safety and Nutrition. J.A. Caswell, ed., Boulder: Westview, 1995.

Gerbouin-Rerolle, P., and M. Chauliac. "Amélioration de la Qualité de la Farine MILEG.” Rapport de Consultation. Bamako, Mali: Institut d'Economie Rurale (IER), 1996.

Haïdara, M. "Rapport a la Commission Technique." Bamako, Mali: SRCVO/DRA/IER, 1989.

Haïdara, M. "L'Utilisation du Mélange de Farine Mil/Niébé dans L'Alimentation Journalière au Mali." Bamako, Mali: La Cellule de Technologie Cerealière (SRCVO/IER), Le Service de Nutrition, INTSORMIL, 1990.

Hayes, D.J., J.F. Shogren, S.Y. Shin, and J.B. Kliebenstein. "Valuing Food Safety in Experimental Auction Markets." Amer. J. Agr. Econ. 77(February 1995):40-53.

Holland, D., and C.R. Wessels. "Predicting Consumer Preferences for Fresh Salmon: The Influence of Safety Inspection and Production Method Attributes." Agr. and Resour. Econ. Rev. 27(April 1998):1-15.

ICRISAT. "Industrial Utilization of Sorghum: Summary Proceedings of a Symposium on the Current Status and Potential of Industrial Uses of Sorghum in Nigeria, 4-6 Dec. 1989, Kano, Nigeria." Patancheru, A.P., India: International Crops Research Institute for the Semi-Arid Tropics (ICRISAT), 1990.

_ . "Utilization of Sorghum and Millets." M.I. Gomez, L.R. House, L.W. Rooney, and D.A.V. Dendy, eds., Patancheru, A.P., India: International Crops Research Institute for the SemiArid Tropics (ICRISAT), 1992

Keïta, M. "Etude de la Relance de la Fabrique Alimentaire du Sahel (F.A.S.)." Bamako, Mali: PAVCOPA, 1996.

Klein, B., and K. B. Leffler. "The Role of Market Forces in Assuring Contractual Performance." J. Polit. Econ. 89(August 1981):615-41.

Ladd, G.W. "Survey of Promising Developments in Demand Analysis: Economics of Product Characteristics." New Directions in Econometric Modeling and Forecasting in U.S. Agriculture G.C. Rausser, ed., New York: Elsevier, 1982.
Lancaster, K.J. "A New Approach to Consumer Theory." J. Polit. Econ. 74(April 1966): 132-57. . Consumer Demand: A New Approach. New York: Columbia University Press, 1971.

Lutter, C.K. "Processed Complementary Foods: Summary of Nutritional Characteristics, Methods of Production and Distribution, and Costs." Food and Nutr. Bull. 21(March 2000):95-100.

Lutter, C.K., and S.L. Huffman, eds. "Special Issue on Processed Complementary Foods in Latin America." Food and Nutr. Bull. 21(March 2000):1-109.

Marchione, T. "Title II Food Aid and the Nutrition of Children in Latin America and the Caribbean." Food and Nutr. Bull. 21(March 2000):65-72.

Mariko, F.S., "Transformation et Commercialisation des Céréales: Expériences UCODAL." Bamako, Mali: UCODAL, 1999.

Martorell, R., and J.-P. Habicht. "Growth in early childhood in developing countries." Human Growth: A Comprehensive Treatise F. Falkner and J.M. Tanner, eds., Vol. 3: Methodology; Ecological, Genetic, and Nutritional Effects on Growth, second edition, pp. 241-62. New York: Kluwer, 1986.

Martorell, R. "The nature of child malnutrition and its long-term implications." Food and Nutr. Bull. 20(September 1999):288-92.

Martorell, R. "Results and Implications of the INCAP Follow-Up Study." J. Nutr. 125(Supplement, April 1995):1127S-38S.

Melton, B.E., W.E. Huffman, J.F. Shogren, and J.A. Fox. "Consumer Preferences for Fresh Food Items with Multiple Quality Attributes: Evidence from an Experimental Auction of Pork Chops." Amer. J. Agr. Econ. 78(November 1996):916-23.

Milgrom, P.R., and J.M. Roberts. "Price and Advertising Signals of Product Quality." J. Polit. Econ. 94(August 1986):796-821.

Mojduszka, E.M., and J.A. Caswell. "A Test of Nutritional Quality Signalling in Food Markets Prior to Implementation of Mandatory Labeling." Amer. J. Agr. Econ. 82(May 2000):298309.

Nelson, P. "Information and Consumer Behavior." J. Polit. Econ. 78(March/April 1970):311-29.

"Advertising as Information." J. Polit. Econ. 81(July/August 1974):729-54.

Nichols, M.W. "Advertising and Quality in the U.S. Market for Automobiles." S. Econ. J. 64(April 1998):922-39.

Onofiok, N.O., and D.O. Nnanyelugo. "Complementary Foods in West Africa: Nutritional Problems and Possible Solutions." Food and Nutr. Bull. 19(March 1998):27-33. 
Penders, C.L., J.M. Staatz, and J.F. Tefft. "How Does Agricultural Development Affect Child Nutrition in Mali?" East Lansing, MI: Department of Agricultural Economics, Michigan State University, 1998.

Porter, R., and L. Shafritz. "Packaged Foods for Complementary Feeding: Marketing Challenges and Opportunities." Washington, DC: Linkages Project, Academy for Educational Development, 1999.

Scrimshaw, N. "The Background and History of Incaparina." Food and Nutr. Bull. 2(April 1980).

Shogren, J.S., S. Shin, D. Hayes, and J. Kliebenstein. "Resolving Differences in Willingness to Pay and Willingness to Accept." Amer. Econ. Rev. 84(March 1994):255-70.

Silva-Barbeau, I., H. Sissoko, M. Berthe, W. Barbeau, and J. Caldwell. "Addressing Child Feeding Concerns of Women Farmers in Mali: Composition and Effects on Child Nutrition of a Locally Developed Complementary Food." Ecology of Food and Nutrition 37(January 1998):1-19.

Smith, L.C., and L. Haddad. "Explaining Child Malnutrition in Developing Countries: A Cross-Country Analysis." Research Report 111. Washington, DC: IFPRI, 2000a.

Smith, L.C. and L. Haddad. "Overcoming Child Malnutrition in Developing Countries." 2020 Discussion Paper 30. Washington DC: IFPRI, 2000b.

Tartanac, F. "Incaparina and other Incaparinabased foods: Experience of INCAP in Central America." Food and Nutr. Bull. 21(March 2000):49-54.

Trèche, S. "Appui a la Formulation d'Aliments de Complément en vue de l'Amélioration de l'Etat Nutritionnel des Enfants au Mali." Rapport Technique de Mission en République du Mali, 15 au 26 mars 1999. Bamako, Mali: Organisation Mondiale de La Santé (OMS), 1999.

UN and IFPRI. "Fourth Report on the World Nutrition Situation." Geneva, Switzerland: ACC/SCN, 2000

Unnevehr, L.J., and N. Hirschhorn. "Food Safety Issues in the Developing World." World Bank Technical Paper No. 469. Washington DC: The World Bank, 2000.

Unnevehr, L.J., and A.P. Villamil. "Long-term Investment in Health: Consumer Information and Functional Foods." Urbana, IL: Department of Agriculture and Consumer Economics, University of Illinois, 1999.

USDA. "Nutrient Database for Standard Reference, Release 12." Washington, DC: USDA/ ARS Nutrient Data Laboratory, 1998.

Van Ravenswaay, E.O., and J.P. Hoehn. "The Impact of Health Risk Information on Food Demand: A Case Study of Alar and Apples." Economics of Food Safety. J.A. Caswell, ed., New York: Elsevier, 1991.

Vickrey, W. "Counterspeculation, Auctions, and Competitive Sealed Tenders." J. of Finan. 16(March 1961):8-37.

Wessells, C.R., and J.G. Anderson. "Consumer Willingness to Pay for Seafood Safety Assurances." J. of Consumer Aff. 29(Summer 1995): $85-107$.

Wise, R.P. "The Case of Incaparina in Guatemala." Food and Nutr. Bull. 2(April 1980).

Wolinsky, A. "Prices as Signals of Product Quality." Rev. Econ. Stud. 50(October 1980): 64758. 